\title{
Nutritional treatment of aged individuals with Alzheimer disease living at home with their spouses: study protocol for a randomized controlled trial
}

\author{
Satu K Jyvakorpi ${ }^{1}$, Taija Puranen ${ }^{1}$, Kaisu H Pitkala ${ }^{2}$ and Merja H Suominen ${ }^{1 *}$
}

\begin{abstract}
Background: Nutritional status often deteriorates in Alzheimer's disease (AD). Less is known about whether nutritional care reverses malnutrition and its harmful consequences in AD. The aim of this study is to examine whether individualized nutritional care has an effect on weight, nutrition, health, physical functioning, and quality of life in older individuals with $A D$ and their spouses living at home.

Methods: AD patients and their spouses (aged $>65$ years) living at home ( $n=202,102$ AD patients) were recruited using central AD registers in Finland. The couples were randomized into intervention and control groups. A trained nutritionist visited intervention couples 4-8 times at their homes and the couples received tailored nutritional care. When necessary, the couples were given protein and nutrient-enriched complementary drinks. All intervention couples were advised to take vitamin D $20 \mathrm{\mu g} /$ day. The intervention lasted for one year. The couples of the control group received a written guide on nutrition of older people. Participants in the intervention group were assessed every three months. The primary outcome measure is weight change. Secondary measures are the intake of energy, protein, and other nutrients, nutritional status, cognition, caregiver's burden, depression, health related quality of life and grip strength.
\end{abstract}

Discussion: This study provides data on whether tailored nutritional care is beneficial to home-dwelling AD patients and their spouses.

Trial registration: ACTRN 12611000018910

Keywords: Nutritional intervention, Malnutrition, Alzheimer disease, RCT, Nutrient intake

\section{Background}

Older individuals with Alzheimer disease (AD) living at home with their spouses are an important target group for nutritional care [1] because weight loss and malnutrition are common problem among them [2-4]. Weight loss is a predictive factor of mortality, and it decreases AD patients' and caregivers' quality of life (QOL) [5,6]. Furthermore AD patients often suffer from frailty, sarcopenia, functional impairments, and comorbidities [7]. Their old spousal caregivers often also have comorbidities and functional

\footnotetext{
* Correspondence: merja.suominen@ravitsemuskuntoutus.fi

${ }^{1}$ Society for Memory Disorders Expertise in Finland, Fredriksberginkatu 2, 00240, Helsinki, Finland

Full list of author information is available at the end of the article
}

disabilities [8]. The possibilities of nutritional care in this patient group remain largely unexplored [9].

Nutritional interventions may have beneficial effects on nutritional status and nutrient intake of $\mathrm{AD}$ patients [6,10-13]. Several controlled studies have suggested that nutritional supplements increase body weight of $\mathrm{AD}$ patients at risk of malnutrition. In an intervention study, weight gain of $\mathrm{AD}$ patients was achieved when nutritional supplements were taken for three months [14]. Similarly, Lauque et al. [10] showed that AD patients' body weight significantly increased with oral nutritional supplements given for three months. A nutrition educational program directed at $\mathrm{AD}$ patients and their spouses

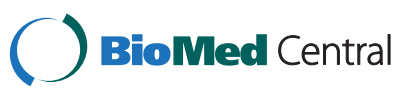


had a positive effect on $\mathrm{AD}$ patients' weights and their cognitive function $[6,13]$.

However, further studies on the benefits of nutritional care and ways of implementing it are needed [15]. Nutritional care and tailored nutritional counselling are important and largely unexplored means of maintaining the health and QOL of AD patients and their caregivers.

Although nutritional care has been examined and proven effective in randomized, controlled settings in a few multinational studies $[1,6,13]$, the effects of nutritional care on functional ability, health, QOL and use of health services among the aged have not been investigated.

The aim of this study is to investigate whether tailored individualized nutritional counselling and care have an effect on the weight, nutrition, functioning, and QOL of $\mathrm{AD}$ patients and their spouses.

\section{Methods}

\section{General design}

This is an intervention trial with a randomized design. The intervention lasts for one year. The intervention group is compared with the control group, who have received a written guide on nutrition of older people. The study has been approved by the Ethics Committee of the Helsinki University Central Hospital and the research committee of KELA (The Social Insurance Institution of Finland). Informed consent has been obtained from each participant and their spousal caregiver before any study procedure.

\section{Participants}

In 2010, a sample of AD patients and their spouses living at the same address in the Vantaa area of Finland was retrieved from the centralized Drug Imbursement Register of the Social Insurance Institution of Finland (KELA). All patients had undergone detailed diagnostic assessments (e. g. cognitive and neuropsychological tests, neuroimaging, and laboratory tests), before receiving reimbursement for their AD medication. The first recruiting letter was sent by KELA with a reply form. Investigators then contacted those who replied. The study purpose and protocol were disclosed to the participants and they were invited to participate. The inclusion criteria were as follows:

- A person with AD living with an aged spouse

- age over 64 years

- being able to use transport (arrive to the study place by taxi)

- being able to stand on a scale

- living in the greater Helsinki area (Helsinki-EspooVantaa)

- adequacy in the Finnish language

- no terminal disease
All AD patients and their spouses showing interest in participation were first contacted and interviewed by phone to confirm the fulfillment of the inclusion criteria. Those couples fulfilling the criteria were invited to the first meeting with a nutritionist, where they were given oral and written information about the study and asked to sign an informed consent. In case of an $\mathrm{AD}$ patient's inability to give informed consent, the spousal caregiver gave proxy consent for both spouses.

\section{Measurements}

The baseline measurements include: background information about demographic data, diagnosis, other potential diseases, falls, fractures, and medication. This information is confirmed from medical records provided by the couples at the first meeting.

The first meeting with baseline measurements takes about two hours. The participants' (AD patient and spouse) weight, height, and grip strength are measured and body mass index (BMI) is calculated. Weight is measured with a portable, calibrated scale (Dexa).

Both spouses' nutritional status is assessed by using Mini nutritional Assessment (MNA) [16] and nutritional anamnesis. In addition, the AD patient and the spouse are both assessed by Minimental State Examination (MMSE) [17]. Health-related quality of life (HRQOL) is measured with 15D- HRQOL form [18] and caregiver's burden with the ZARIT form [19].

The AD patients are assessed by Clinical Dementia Rating Scale (CDR) [20], Neuropsychiatric Inventory (NPI) $[21,22]$, Cornell depression test [23], and Instrumental activities of daily living (IADL) [24] by interviewing the spouse. The spouse is also assessed by IADL. While the spouse is being interviewed, the $\mathrm{AD}$ patient has the opportunity to take part in day-time group activities for older people provided by the city of Vantaa in Simonkylä.

A trained nutritionist gives AD patients' spouses oral and written instructions on how to keep a food diary for three days. They receive food measures of $100 \mathrm{ml}$, $15 \mathrm{ml}$, and $5 \mathrm{ml}$ to measure amounts of food items consumed. After investigators receive the completed food diary, the nutritionist checks it and calls the couple to ensure that the amounts of food items, cooking methods, and, for example the type of milk or fat are recorded correctly. The food diaries are analyzed using a Nutrica 3.11 [25] program developed for this purpose.

\section{Randomization}

The couples are randomized into clusters of six. The randomization is performed as follows: investigators write down identification numbers of each couple on six pieces of papers, which are then folded so that the numbers cannot be seen. A person unrelated to the investigation then chooses three pieces of paper and the couples 
with these ID numbers are signed to the intervention group.

All participating couples are assessed at baseline and at the end of the trial with methods described previously. In addition, all AD patients' and their spouses' weights are measured at six months.

The nutritionist visits and weighs the intervention couples in their homes also at 3 and 9 months. Nutritional counseling and care are tailored according to each intervention couples needs and consists of 4-8 home visits by the nutritionist Table 1 .

\section{Intervention}

The nutritionist analyzes the 3-day food diaries recorded by the couples. On the basis of the food diary analysis,
MNA, home visits and nutritional anamnesis, the nutritionist develops a plan for individualized nutritional care and discusses nutrition with the couple.

The objective of nutritional care is not to change the $\mathrm{AD}$ patients' and spouses' food habits completely, but to correct possible inadequacies in their diet. The main objective is to recommend food items that they are familiar with and which are already part of their daily diet. If nutrient deficiencies on the basis of food diaries or further discussions with the spouse are noted that are difficult to correct with food, a supplement is recommended. Nutritional care has the objective of ensuring a sufficient intake of energy, protein, and other nutrients. To increase protein in the diet, good protein sources are recommended, and if the couple seems unable to increase energy, protein, and/or other

Table 1 Study assessments and timetable

\begin{tabular}{|c|c|c|c|c|c|c|}
\hline Assessment & Baseline assessments & Telephone interview & 3-month visit & 6-month visit & 9-month visit & 12-month assessment \\
\hline \multicolumn{7}{|l|}{ AD patient } \\
\hline Inclusion criteria & & $x$ & & & & \\
\hline Background information $^{1}$ & $x$ & & & & & $x$ \\
\hline Nutrition anamnesis & $x$ & & & & & $x$ \\
\hline 3-day food diaries ${ }^{1}$ & $x$ & $x$ & & & & $x$ \\
\hline CDR & $x$ & & & & & $x$ \\
\hline MMSE & $x$ & & & & & $x$ \\
\hline$\overline{M N A}$ & $x$ & & & & & $x$ \\
\hline Weight, BMI & $x$ & & $x^{2}$ & $x$ & $x^{2}$ & $x$ \\
\hline Grip strength & $x$ & & & & & $x$ \\
\hline NPI & $x$ & & & & & $x$ \\
\hline Cornell & $x$ & & & & & $x$ \\
\hline IADL & $x$ & & & & & $x$ \\
\hline $15 D^{1}$ & $x$ & & & & & $x$ \\
\hline Use of health services & & & & $x$ & & $x$ \\
\hline \multicolumn{7}{|l|}{ Spouse } \\
\hline Background information $^{1}$ & $x$ & & & & & $x$ \\
\hline Nutrition anamnesis & $x$ & & & & & $x$ \\
\hline 3-day food diaries ${ }^{1}$ & $x$ & $x$ & & & & $x$ \\
\hline Zarit $^{1}$ & $x$ & & & & & $x$ \\
\hline MNA & $x$ & & & & & $x$ \\
\hline MMSE & $x$ & & & & & $x$ \\
\hline $15 \mathrm{D} \mathrm{HRQOL}^{1}$ & $x$ & & & & & \\
\hline IADL & $x$ & & & & & $x$ \\
\hline Weight, BMI & $x$ & & $x^{2}$ & $x$ & $x^{2}$ & $x$ \\
\hline Grip strength & $x$ & & & & & $x$ \\
\hline Use of health services & & & & $x$ & & $x$ \\
\hline
\end{tabular}

${ }^{1}$ filled at home.

${ }^{2}$ only in intervention group

AD Alzheimer's disease, CDR degree of dementia [20], MMSE Mini mental state examination [17], MNA Mini Nutritional Assessment [16], BMI body mass index, NPI Neuropsychiatric inventory [21,22], Cornell depression test [23], IADL Instrumental activities of daily living [24], 15 D HRQOF [18], Zarit Zarit burden scale [19]. 
nutrients in their diet, complementary dietary drinks consisting of protein and other nutrients are given to them for daily use. The complementary drink [Nutridrink protein (200 ml; $300 \mathrm{kcal}, 20 \mathrm{~g}$ protein) or Nutridrink compact (125 ml; $300 \mathrm{kcal}$ and $12 \mathrm{~g}$ protein)] is offered once daily.

All intervention couples are also advised to take $20 \mu \mathrm{g}$ of supplemental vitamin D daily. The amount of calcium in the diets of participants is also reviewed. The nutritionist visits the couples at least four times and weighs them with a portable scale at 3,6 , and 9 months. At baseline and at the final meeting at 12 months, the weights are also measured along with other assessments. The nutritionist can visit couples' homes more frequently according to their needs. The intervention couples also receive oral and written advice on exercise to strengthen muscles that is easy to perform at home. The intervention lasts for one year (Figure 1).

In addition to the nutritional counseling, the couples in the intervention group have the opportunity to take part in a group meeting discussing nutritional issues. Couples willing to participate receive a free taxi-card to arrive to and from the meeting.

\section{Outcome}

A primary outcome measure is change in $\mathrm{AD}$ patients' weights. Secondary outcomes are changes in their energy, protein, and other nutrient intakes retrieved from food diaries, AD patients' functional ability [20,24], cognitive functioning (MMSE) [19], neuropsychiatric symptoms (NPI, Cornell) [21-23], and caregiver burden (Zarit burden scale) [17]. In addition, HRQOL [16] and use of health services will be assessed during the on year follow-up.

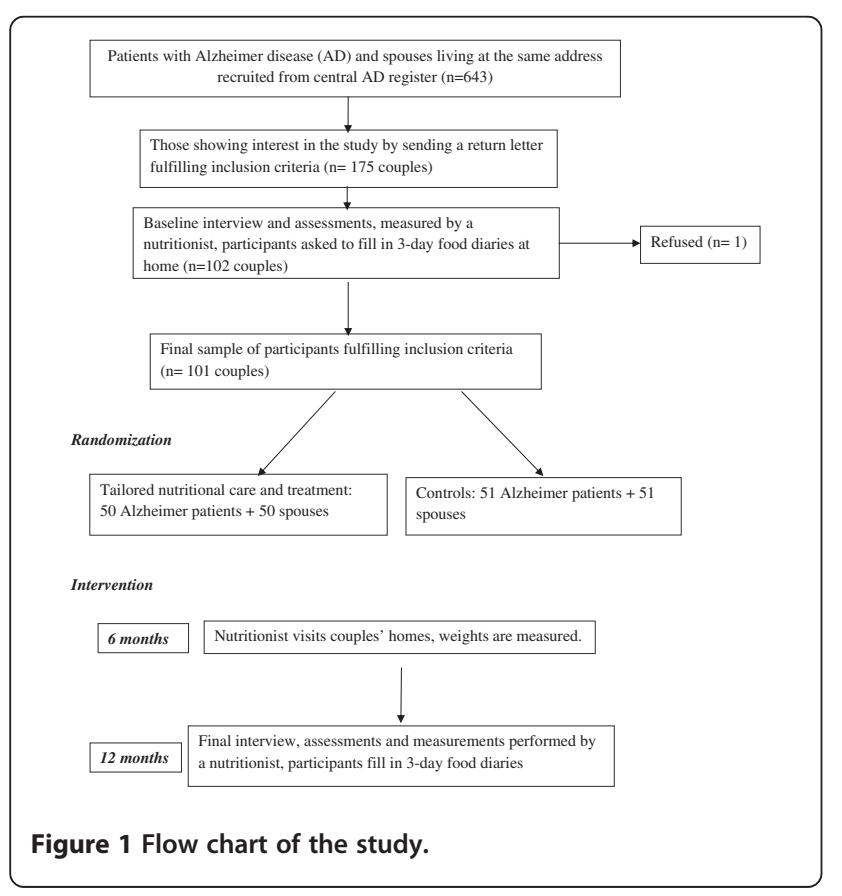

\section{Statistical analyses}

Sample size is calculated based on AD patient's expected weight change, with a standard deviation of $3.6 \mathrm{~kg}$ [6], and type I error of $5 \%, 80 \%$ power. For an expected weight difference between intervention and control patients of $2 \mathrm{~kg}, 50$ patients are needed in each group to show statistical difference. Data will be analyzed on an intention to treat basis. Imputation methods of "the last observation carried forward" (LOCF) and worst rank score will be used.

Data are analyzed using a SPSS statistical program. Intervention and control groups will be compared at baseline; categorical variables will be tested by a Chisquared test $\left(\mathrm{X}^{2}\right)$ or Fischer's exact test, and continuous variables by two-sided t-test or Mann-Whitney U-test as appropriate.

Qualitative data will be collected by interviewing subjects during the nutritionist's visits. The case studies will be transcribed and content analyses carried out. The aim of the analyses will be to analyze difficulties and positive factors in the daily lives of the families that may explain differences in success of nutritional care between subjects.

All data will be securely stored at The Society for Memory Disorders Expertise in Finland. Computerized data will be available only to the members of the research team. The analyzed data will be cleared of all the recognition information, and only ID numbers will be used.

\section{Discussion}

This intervention trial investigates the effect of individualized, home-based tailored nutritional care on homedwelling $\mathrm{AD}$ patients and their aged spouses. A nutritionist visits the intervention couples in their homes 4-8 times according to their nutritional needs. In addition, the intervention group is given oral and written counseling on exercise and how to perform daily exercise routine to strengthen muscles. If the intervention couple is unable to complement their diet naturally and clear deficiencies in protein and/or other nutrients are observed, the couple will be given complementary daily drinks that contain energy, protein, and other nutrients. Dietary supplements are recommended to $\mathrm{AD}$ patient and spouse when necessary. In addition, intervention couples are advised to take a $20 \mu \mathrm{g}$ vitamin D supplement daily year round. The control group is given a written guide on nutrition of the older people.

Our study has several strengths. All AD patients have an established diagnosis of AD; they were recruited from the Finnish drug registry. As $\mathrm{AD}$ is a risk factor for deterioration of nutritional status, this intervention enables this problem to be dealt with at early stage of the disease. Old spouses also often have multiple diseases and 
disabilities, and thus, are an important target group for nutritional care. Tailored nutritional care may enable the aged couple to live in their home longer. Findings of this trial are directly applicable to real life, allowing nutritionists and healthcare professionals to focus on nutritional interventions for the older people. Tailored nutritional intervention that addresses the nutritional needs of $\mathrm{AD}$ patients and their caregivers is described in detail.

The study also has potential drawbacks. First, our study population is old and frail with many comorbidities, thus, being vulnerable to various complications. Second, a sufficient difference may be difficult to obtain between intervention and control groups. Contamination of the control group is probably not a problem because home-based nutritional interventions are not available in Finland to AD patients and their spouses.

To our knowledge, this study is the first of its kind conducted in Finland; nutritional interventions in a homebased setting before for $\mathrm{AD}$ patients and their spouses have not been performed. Our study provides new and detailed information on intervention methods that can be implemented to decrease malnutrition and its adverse effects in frail old individuals. This gives caregivers and healthcare personnel information on nutritional treatment possibilities. Optimally, nutritional rehabilitation will support older persons' nutrition, maintain or increase functional ability, reduce the use of health services, and improve QOL.

\section{Trial status}

Trial is still ongoing. Patient recruitment has been completed and follow-up is being conducted.

\section{Abbreviations}

AD: Alzheimer disease; BMI: Body Mass Index; CDR: Clinical Dementia Rating Scale; HRQOL: Health-related quality of life; IADL: Instrumental activities of daily living; MMSE: Minimental State Examination; MNA: Mini Nutritional assessment; NPI: Neuropsychiatric Inventory.

\section{Competing interests}

All the authors declare that they have no competing interests.

\section{Authors' contributions}

1. Conception and design (SKJ, TP, KHP, MHS). 2. Acquisition of data (SK, TP, MHS) 3. Drafting the article or revising it critically (SK, TP, KHP, MHS). 4. Final approval of the version to be submitted (SKJ, TP, KHP, MHS). MHS is the guarantor.

\section{Acknowledgements}

This study is supported by the Finland's Slot Machine Association. The sponsor did not have any role in the design of the study, neither in the collection, nor in the writing the report.

\section{Author details}

${ }^{1}$ Society for Memory Disorders Expertise in Finland, Fredriksberginkatu 2, 00240, Helsinki, Finland. ${ }^{2}$ Unit of General Practice, Helsinki University Central Hospital and Department of General Practice and Primary Health Care, University of Helsinki, PO Box 2000014, Helsinki, Finland.

Received: 16 January 2012 Accepted: 10 April 2012

Published: 24 May 2012

\section{References}

1. Shatenstein B, Kergoat MJ, Reid I, Chicoine ME: Dietary intervention in older adults with early-stage Alzheimer dementia: early lessons learned. J Nutr Health Aging 2008, 12:461-469. Review.

2. Seth R: Weight loss in Alzheimer's disease. Int J Geriatr Psychiatry 1994, 9:605-620.

3. Cronin-Stubbs D, Beckett LA, Scherr PA, Field TS, Chown MJ, Pilgrim DM, Bennett DA, Evans DA: Weight loss in people with Alzheimer's disease: a prospective population based analysis. BMJ 1997, 314:178-179.

4. Gillette-Guyonnet S, Nourhashemi F, Andrieu S, de Glisezinski I, Ousset PJ, Riviere D, Albarede JL, Vellas B: Weight loss in Alzheimer disease. Am J Clin Nutr 2000, 71(Suppl):637-642.

5. White $H$, Pieper C, Schmader K: The association of weight change in Alzheimer's disease with severity of disease and mortality: a longitudinal analysis. J Am Geriatr Soc 1998, 46:1232-1234.

6. Rivière $S$, Gillette-Guyonnet $S$, Voisin $T$, Reynish $E$, Andrieu $S$, Lauque S, Salva A, Frisoni G, Nourhashemi F, Micas M, Vellas B: A nutritional education program could prevent weight loss and slow cognitive decline in Alzheimer's disease. J Nutr Health Aging 2001, 5:295-299.

7. Pedersen AN, Ovesen L, Schroll M, Avlund K, Era P: Body composition of 80 -years old men and women and its relation to muscle strength, physical activity and functional ability. J Nutr Health Aging 2002, 6:413-420.

8. Raivio M, Eloniemi-Sulkava U, Laakkonen ML, Saarenheimo M, Pietilä M, Tilvis R, Pitkälä K: How do officially organized services meet the needs of elderly caregivers and their spouses with Alzheimer's disease? Am J Alzheimers Dis Demen 2007, 22:360-368.

9. Guigoz Y: The Mini Nutritional assessment $\left(M N A^{\circledR}\right)$ review of the literature - what does it tell us? J Nutr Health Aging 2006, 10:466485.

10. Lauque S, Arnaud-Battandier F, Gillette S, Plaze JM, Andrieu S, Cantet C, Vellas B: Improvement of Weight and Fat-Free Mass with Oral Nutritional Supplementation in Patients with Alzheimer's Disease at Risk of Malnutrition: A Prospective Randomized Study. JAGS 2004, 52:1702-1707.

11. Milne A, Avenell A, Potter J: Meta-Analysis: Protein and energy supplementation in older people. Ann Intern Med 2006, 144:37-48.

12. Nijs KA, de Graaf C, Siebelink E, Blauw YH, Vanneste V, Kok FJ, van Staveren WA: Effect of family-style meals on energy intake and risk of malnutrition in dutch nursing home residents: a randomized controlled trial. J Gerontol A Biol Sci Med Sci 2006, 61:935-942.

13. Shatenstein $B$, Kergoat MJ, Reid I: Poor nutrient intakes during 1-year follow-up with community-dwelling older adults with early-stage Alzheimer dementia compared to cognitively intact matched controls. J Am Diet Assoc 2007, 107:2091-2099.

14. Salas-Salvadó J, Torres M, Planas M, Altimir S, Pagan C, Gonzalez ME, Johnston S, Puiggros C, Bonada A, García-Lorda P: Effect of oral administration of a whole formula diet on nutritional and cognitive status in patients with Alzheimer's disease. Clin Nutr 2005, 24:390-397.

15. Baldwin C, Weekes CE: Dietary advice with or without oral nutritional supplements for disease-related malnutrition in adults. Cochrane Database Syst Rev 2011, 9:CD002008.

16. Guigoz Y, Launque $S$, Vellas BJ: Identifying the elderly at risk for malnutrition the Mini Nutritional Assessment. Clin Geriatr Med 2002, 18:737-757

17. Folstein MF, Folstein SE, Mchugh PR: "Mini-mental-state". A practical method for grading the cognitive state of patients for the clinician. $J$ Psychiatr Res 1975, 12:189-198.

18. Sintonen $H$ : The $15 \mathrm{D}$ instrument of health-related quality of life: properties and applications. Ann Med 2001, 33:328-336.

19. Zarit SH, Reever KE, Bach-Peterson J: Relatives of the impaired elderly: correlates of feelings of burden. Gerontologist 1980, 20:649-655.

20. Hughes CP, Berg L, Danziger WL, Coben LA, Martin RL: A new clinical scale for the staging of dementia. Br J Psychiatry 1982, 140:566-572.

21. Cummings JL, Mega M, Gray K, Rosenberg-Thompson S, Carusi DA, Gornbein J: The Neuropsychiatric Inventory: comprehensive assessment of psychopathology in dementia. Neurology 1994, 44:2308-2014.

22. Cummings $\mathrm{J}$ : The Neuropsychiatric Inventory: assessing psychopathology in dementia patients. Neurology 1997, 48(Suppl):10-16. 
23. Alexopoulos GS, Abrams RC, Young RC, Shamoian CA: Cornell scale for depression in dementia. Biol Psychiatry 1988, 23:271-284.

24. Lawton MP, Brody EM: Assessment of older people: self-maintaining and instrumental activities of daily living. Gerontologist 1969, 9:179-186.

25. Rastas M, Seppänen R, Knuts L-R, Karvetti R-L, Varo P: Ruokien

ravintoainesisältö [Nutrient Composition of Foods]. Turku: Kansaneläkelaitos; 1997.

doi:10.1186/1745-6215-13-66

Cite this article as: Jyvakorpi et al: Nutritional treatment of aged

individuals with Alzheimer disease living at home with their spouses:

study protocol for a randomized controlled trial. Trials 2012 13:66.

\section{Submit your next manuscript to BioMed Central and take full advantage of:}

- Convenient online submission

- Thorough peer review

- No space constraints or color figure charges

- Immediate publication on acceptance

- Inclusion in PubMed, CAS, Scopus and Google Scholar

- Research which is freely available for redistribution 